\title{
Do "léxico gay" à Linguística Queer: desestabilizando a norma homossexual oculta nas Teorias Queer $^{1}$
}

\author{
Elizabeth Sara Lewis \\ Universidade Federal do Estado do Rio de Janeiro (UNIRIO), \\ Rio de Janeiro, Rio de Janeiro, Brasil \\ elizabeth.lewis@unirio.br \\ https://orcid.org/0000-0001-6303-5727
}

DOI: http://dx.doi.org/10.21165/el.v47i3.2049

\begin{abstract}
Resumo
O presente artigo examina se, apesar de permitir maiores desconstruções e desnaturalizações das categorias de sexualidade que usamos hoje em dia, a Linguística Queer sofre de um dos problemas que afeta os Estudos Queer em geral: uma "norma homossexual oculta" (GUSTAVSON, 2009), ou priorização do estudo de homens gays. Embora a Linguística Queer tenha prestado maior atenção às performances discursivas de lésbicas, ainda há uma lacuna de pesquisas sobre performances de outras "orientações" sexuais e performances discursivas relacionadas a práticas sexuais que desestabilizam o binário heterossexual/homossexual. Portanto, pretende-se discutir alguns exemplos de estudos recentes realizados no campo da Linguística Queer que vão além da "norma oculta homossexual": um sobre performances de mulheres bissexuais e outro sobre performances de adeptos/as da prática de pegging.

Palavras-chave: Linguística Queer; norma homossexual oculta; performatividade.

From the "gay lexicon" to Queer Linguistics: Destabilizing the hidden homosexual norm in Queer Theories
\end{abstract}

\begin{abstract}
This article examines whether Queer Linguistics, although it permits greater deconstruction and denaturalization of the sexuality categories we frequently use today, suffers from one of the issues that affects Queer Studies in general: a "hidden homosexual norm" (GUSTAVSON, 2009), or privileging of the study of gay men. Although Queer Linguistics has paid more attention to the discursive performances of lesbians, research on performances of other sexual "orientations" and on discursive performances related to sexual practices that destabilize the heterosexual/homosexual binary are still lacking. Therefore, we intend to discuss a few examples of recent studies realized in the field of Queer Linguistics that go beyond the "hidden homosexual norm": one study about performances of bisexual women and another about performances of people who engage in the practice of "pegging".
\end{abstract}

Keywords: Queer Linguistics; hidden homosexual norm; performativity.

\section{Das Teorias Queer à Linguística Queer - as mesmas críticas se aplicam?}

Desde quando a Teoria Queer surgiu nos anos 1990, começou a espalhar-se ao redor do mundo, resultando em várias vertentes e variedades locais; por isso, hoje em dia podemos falar de Teorias Queer no plural. Essas teorias foram aplicadas a uma grande

\footnotetext{
${ }^{1}$ Palestra proferida no $65^{\circ}$ GEL na mesa redonda “Linguagens Queer: aproximações possíveis?”.
} 
variedade de disciplinas, incluindo a Educação, Antropologia, Sociologia e, mais recentemente, a Linguística. A proliferação das Teorias Queer também foi acompanhada, como acontece com toda teoria, por uma série de críticas. No presente artigo, após uma breve introdução às Teorias Queer e à Linguística Queer, pretendemos olhar para uma dessas críticas - a existência uma "norma homossexual oculta" (GUSTAVSON, 2009), ou priorização do estudo de homens gays - e discutir se aplica-se também à Linguística Queer ou se ela está conseguindo superá-la, e como. Para este fim, faremos, num primeiro momento, uma breve revisão bibliográfica de estudos sobre linguagem e sexualidade e trabalhos de Linguística Queer. Num segundo momento, olharemos para alguns exemplos concretos no campo da Linguística Queer: um estudo sobre as performances identitárias de mulheres bissexuais no movimento LGBT no Rio de Janeiro face a preconceitos bifóbicos e outro sobre adeptos/as de pegging, uma prática sexual na qual uma mulher penetra um homem heterossexual no ânus usando um dildo segurado por um cinto.

\section{Breve introdução às Teorias Queer e à Linguística Queer}

A primeira vertente das Teorias Queer surgiu nos Estados Unidos nos anos 1990, por meio de uma relação recíproca entre o ativismo político de grupos militantes antiassimilacionistas, como Queer Nation e Act Up, e o trabalho acadêmico de teóricos/as como Teresa de Lauretis, Judith Butler, Eve Kosofsky Sedgwick e Steven Seidman, que foram influenciados/as pelo pós-estruturalismo e pelas teorias feministas. Na visão de De Lauretis (1991, p. iv, tradução nossa), que cunhou o termo "Queer Theory", os Estudos Queer partem da

[...] premissa especulativa de que a homossexualidade não deve continuar a ser vista como algo marginal em relação a uma forma dominante e estável da sexualidade (a heterossexualidade) contra a qual seria definida ou por oposição ou desviante vis-à-vis uma sexualidade correta e natural (i.e. a sexualidade institucionalizada reprodutiva) [...].

Apesar do surgimento de várias vertentes ao redor do mundo, podemos dizer que em geral as Teorias Queer hoje em dia procuram revelar e desestabilizar naturalizações e normatividades. Para Guacira Lopes Louro (2004, p. 38-39), por exemplo,

[...] queer significa colocar-se contra a normalização - venha ela de onde vier. Seu alvo mais imediato de oposição é, certamente, a heteronormatividade compulsória da sociedade; mas não escaparia de sua crítica a normalização e a estabilidade propostas pela política de identidade do movimento homossexual dominante. Queer representa claramente a diferença que não quer ser assimilada ou tolerada, e, portanto, sua forma de ação é muito mais transgressiva e perturbadora.

Como mencionamos, desde sua inauguração nos anos 1990, o interesse nas Teorias Queer se proliferou, e essas teorias foram aplicadas a múltiplas disciplinas incluindo, recentemente, a Linguística. Porém, mesmo antes da sua chegada "formal" a essa área, podemos dizer que as Teorias Queer já tinham uma forte base linguística, devido ao conceito da performatividade de gênero proposto por Butler (2003 [1990]), que parte da teoria dos atos de fala de John L. Austin (1990 [1962]). Austin inicialmente dividiu os atos de fala em duas categorias: constativos, ou atos de fala que descrevem, relatam ou constatam alguma coisa, e que podem ser verdadeiros ou falsos, e performativos, ou atos de fala que não são descrições, mas realizam ações, e são bemsucedidos ou malsucedidos em vez de verdadeiros ou falsos. Mais tarde, Austin desfez 
essa distinção, propondo que talvez não fosse possível distinguir tão facilmente entre constativos e performativos, pois descrever algo também seria um tipo de ação. $\mathrm{O}$ autor, porém, nunca desenvolveu plenamente essa ideia; assim, Butler começou onde Austin parou, levando o rompimento da distinção entre constativos e performativos ao próximo nível. Para a autora, muitos atos de fala, como "É uma menina" e "Meninos não choram", embora pareçam simples descrições, na verdade realizam ações no mundo. Para facilitar a compreensão, podemos comparar essa ideia de Butler às implicaturas conversacionais de Grice (1982 [1967]). Um enunciado como “Nossa, está frio aqui!”, embora pareça uma simples descrição, pode na verdade ser um pedido implícito de desligar o ar ou emprestar um casaco - ou ser interpretado como tal, mesmo se essa não fosse a intenção do/a falante. Assim, enunciados como "É uma menina" fazem algo parecido - não simplesmente descrevem o corpo de uma criança; reproduzem, performativamente, ideias sobre gêneros e sexualidades que, através da repetição ao longo do tempo, ganham a aparência de ser naturais e normais. ${ }^{2}$ A revelação e desestabilização de tais naturalizações e normalizações, como vimos na citação de Louro acima, é um dos objetivos das Teorias Queer.

Levando em consideração essas bases linguísticas das Teorias Queer, podemos agora discutir a Linguística Queer, que surgiu ao final dos anos 1990. De acordo com Borba, "O objetivo principal da L[inguística] Q[ueer] é investigar como indivíduos considerados não-normativos negociam suas identidades dentro dos constrangimentos discursivos da heteronormatividade ao repeti-la ou subvertê-la através de suas performances linguísticas" (2015, p. 99-100). ${ }^{3} \mathrm{O}$ autor identifica, ainda, duas fases na Linguística Queer. Num primeiro momento, a Linguística Queer podia ser caracterizada como a aplicação da Teoria Queer (estadunidense) à Linguística ou, mais especificamente, ao estudo da linguagem-em-uso (BARRETT, 2002). As pesquisas desse primeiro momento focavam nas práticas linguísticas de seres vistos como abjetos por causa de suas performances de gênero e sexualidade, como veremos mais adiante. No segundo momento, passou-se a estudar criticamente a heteronormatividade através de uma visão linguística, sempre desafiando a ideia da heterossexualidade como a norma (MOTSCHENBACHER, 2011). Os estudos desse segundo momento tendem a olhar para a subversão e/ou reforço da heteronormatividade no discurso e as possibilidades para ação social. Assim, a Linguística Queer "tem se configurado como uma área de investigação que estuda o espaço semântico-pragmático entre os discursos dominantes (i.e. heteronormatividade) e a performance linguística situada" (BORBA, 2015, p. 94).

\footnotetext{
${ }^{2}$ É importante também distinguir entre performances (identitárias) e performatividade. Uma performance, no sentido butleriano, é um ato discursivo-corporal que faz parte de um processo de (re)produção (ou subversão) de papéis e normas sociais (BUTLER, [1990] 2003). A performatividade é o processo de repetição de performances que resulta na normalização e naturalização de certas ideias e modos de ser, mas também abre brechas para subversões que, ao serem repetidas, podem levar à mudança social.

${ }^{3}$ A heteronormatividade é uma ordem baseada na centralidade da família heterossexual reprodutiva, com regras que "normatizam e naturalizam a heterossexualidade como modo 'correto' de estruturar o desejo" (BORBA, 2015, p. 96), assim estabelecendo e coagindo como as pessoas devem se comportar, desejar etc. Pessoas homossexuais, bissexuais e transexuais, em particular, tendem a sofrer marginalizações por não se encaixarem na heteronorma, porém, é importante lembrar que a "[h]eteronormatividade também prescreve uma certa maneira de viver a heterossexualidade e [...] pessoas heterossexuais que fogem daquilo que é considerado 'normal' para uma pessoa heterossexual (desde pessoas com 'fetiches' sexuais a pessoas que decidem não ter filhos...) também podem sofrer discriminações e pressões de se conformarem à norma" (LEWIS, 2017, p. 173).
} 


\section{A "norma homossexual oculta": crítica às Teorias Queer... e à Linguística Queer?}

As Teorias Queer, particularmente a vertente estadunidense, têm passado por uma série de críticas. Aqui, concentrar-nos-emos sobre uma crítica pouca conhecida, porém, de extrema importância: o fato que, como observam Laura Erickson-Schroth e Jennifer Mitchell (2009, p. 298, tradução nossa), "na sua tentativa de teorizar identidades nãoheterossexuais, a teoria queer tem teorizado, infelizmente, somente a identidade homossexual". Embora as Teorias Queer ofereçam as bases para questionar a naturalização do sexo, gênero e sexualidade e para desestabilizar visões normativas e limitadoras, a maioria das pesquisas continua a privilegiar o estudo do desejo homossexual, reforçando o que Malena Gustavson (2009, p. 414, tradução nossa) chama de uma "norma homossexual oculta na teoria queer". O foco das críticas das três autoras mencionadas é a imensa e preocupante falta de estudos sobre a bissexualidade nos Estudos Queer. A bissexualidade, quando não totalmente esquecida, é geralmente mencionada só como parte de uma lista ("gays, lésbicas, bissexuais, transexuais, transgêneros, intersexuais...”) ou sigla (LGBT), mas não examinada, questionada e problematizada profundamente. Assim, o fato de poucos Estudos Queer terem tratado de bissexualidade só reforça o binário heterossexual/homossexual que a Teoria Queer supostamente quer desestabilizar. Uma crítica parecida também poderia ser levantada para outras categorias menos problematizadas, como assexual, pansexual, omnissexual etc.

Embora o alvo das críticas das autoras acima mencionadas, Gustavson (2009) e Erickson-Schroth e Mitchell (2009), seja (com razão) o problema das Teorias Queer reforçarem o binário heterossexual/homossexual ao não prestarem atenção adequada à bissexualidade, eu gostaria de frisar outra questão. A "norma homossexual oculta" não só invisibiliza a bissexualidade; também invisibiliza outras performances identitárias de sexualidade e outras práticas sexuais. Enquanto os Estudos Queer pretendem desconstruir as categorias que usamos atualmente para apreender as sexualidades e nos referirmos às identidades de "orientação sexual" (hétero, gay, lésbica, bi etc.), tendem a não prestar atenção suficiente (ou nenhuma) a performances de sexualidade e práticas sexuais que não se encaixam em tais rótulos ou vão além deles - rótulos que sempre definem a sexualidade com base no gênero dos/as parceiros/as sexuais. Seguindo Sedgwick (1990), podemos pensar a sexualidade através de uma grande variedade de dimensões, incluindo a preferência para certos tipos físicos, idades, atos sexuais, tipos de estimulação, número de participantes, relações de poder etc.; porém, ao usar sempre certas categorias de "orientação sexual", focamos unicamente na dimensão do gênero do/a parceiro/a.

A questão central que gostaria de levantar é, então: se os Estudos Queer em geral não realizam o potencial das Teorias Queer de desestabilizarem categorias naturalizadas de sexualidade, a Linguística Queer também segue esta tendência? Para responder a essa questão, vamos começar olhando para a história da Linguística Queer e fazendo uma breve revisão bibliográfica.

\section{Do "Léxico Gay" à Linguística Queer: uma breve revisão da literatura sobre linguagem e sexualidade}

O campo específico da Linguística Queer foi inaugurado depois da segunda metade dos anos 1990. Antes desse momento, os poucos estudos sobre linguagem e sexualidade geralmente falavam somente do léxico empregado por pessoas 
homossexuais. ${ }^{4}$ Vários glossários de palavras, frases e gírias homossexuais foram publicados, a maioria dos quais se concentrava sobre a fala de homens brancos homossexuais, por exemplo: o capítulo "A Lexicon of Homosexual Slang" de Cory e Leroy (1963), o livro The Lavender Lexicon: Dictionary of Gay Words and Phrases de Strait and Associates (1964), o livro The Queens' Vernacular: A Gay Lexicon de Rodgers (1972) e o artigo "The Argot of the Homosexual Subculture" de Farrell (1972). Depois, alguns/umas autores/as se interessaram por outros aspectos da "linguagem gay e lésbica", incluindo alternâncias de código (LUMBY, 1976), insultos (MURRAY, 1979), a "fala homossexual" (CHESEBRO, 1981), fenômenos paralinguísticos (WEBBINK, 1981) e padrões de ênfase (MOONWOMON, 1985).

Portanto, até os anos 1990, os poucos estudos sobre língua(gem) e sexualidade geralmente discutiam somente o léxico empregado por pessoas que se identificavam como homossexuais, particularmente homens gays brancos. Como frisa Queen (2002), um trabalho de Linguística, como aqueles mencionados acima, sobre a fala de sujeitos LGBTs ou "queer" não é necessariamente um trabalho de Linguística Queer; para ser assim considerado, deve partir da visão da Teoria Queer. Assim, desde a segunda metade dos anos 1990, vários/as autores/as começaram a preencher as lacunas na literatura prévia, investigando não somente a linguagem usada por pessoas performando certas identidades vistas como LGBTs ou "queer", mas a construção performativa dessas identidades através da linguagem. Chegamos, assim, à Linguística Queer.

Considera-se que o campo da Linguística Queer foi oficialmente inaugurado em 1997 com a publicação do livro Queerly Phrased: Language, Gender, and Sexuality, organizado por Anna Livia e Kira Hall. O livro é composto por 25 capítulos escritos por vários/as autores/as que examinam como as identidades de gênero e sexualidade são construídas discursivamente, partindo da teoria da performatividade de gênero de Butler. Esses capítulos são divididos em três seções: primeiro, "lexicalidade liminar", cujos trabalhos discutem os itens lexicais que são cultural e ideologicamente significativos na denotação de identidades sexuais "alternativas"; segundo, "fala queer", cujos capítulos discutem as estratégias discursivas e as características específicas da fala de gays e lésbicas ao mesmo tempo que perguntam-se se certa fala característica deve ser usada exclusivamente por esses grupos para ser considerado um traço homossexual; e, por último, a seção "manipulação do gênero linguístico", cujo foco cai em como o sistema linguístico-gramatical de gênero é usado, ou manipulado, por sujeitos "sexualmente ambíguos", desde pessoas transexuais a pessoas intersexuais, desde as hijras da Índia a gays parisienses aos 'yan daudu da Nigéria. A seção visa a explorar como o gênero gramatical pode, por um lado, reforçar a ideia que o mundo seja inerentemente generificado, mas, por outro, possibilitar que as pessoas expressem suas relações com o conceito de gênero. Desta maneira, há uma representação relativamente ampla de diferentes performances de gênero ${ }^{5}$; porém, quando olhamos para questões de

\footnotetext{
${ }^{4}$ Existia, também, ampla literatura sobre linguagem e gênero antes da inauguração da Linguística Queer. Aqui, porém, concentrar-nos-emos nos estudos sobre linguagem e sexualidade (mas sempre reconhecendo que gênero e sexualidade são construções sociais fortemente imbricadas), já que a crítica da "norma homossexual oculta" foca na questão da sexualidade.

${ }^{5}$ Apesar de elogiar a variedade de representações de gênero, é importante lembrar, como afirma Raewyn Connell (2016, p. 39-40), que as “discussões sobre ‘terceiros gêneros' ou grupos envolvidos em transição de gênero [...] [têm se tornado] quase uma moda nas teorias pós-estruturalistas do gênero no Norte Global. Há uma literatura do Norte que tende a mesclar todos esses grupos, incluindo as pessoas hijira na Índia, as pessoas kathoey na Tailândia e as travestis na América do Sul, numa única ampla categoria de
} 
sexualidade (embora essas duas categorias estejam imbricadas), vemos uma diversidade menor de representação e discussão de possibilidades de sexualidade.

No livro Queerly Phrased, os capítulos sobre performances identitárias de sexualidade concentram-se sobre pessoas que se identificam como gays e lésbicas (vale a pena notar a presença de vários capítulos que se concentram sobre questões de lesbianidade, incluindo uma reprodução do artigo clássico "Toward the Study of Lesbian Speech” de Moonwomon-Baird, “'I Don’t Speak Spritch': Locating Lesbian Language” de Queen, "Narrative Iconicity in Electronic-Mail Lesbian Coming-Out Stories" de Wood, e "Deaf Identity, Lesbian Identity: Intersections in a Life Narrative" de Neumann, entre outros). Isso exemplifica a caracterização da primeira fase da Linguística Queer levantada por Borba que vimos anteriormente: a Linguística Queer como a aplicação das Teorias Queer à Linguística, cujo foco "recaía na descrição de como seres abjetos [...] utilizavam a linguagem em diversas práticas sociais" e como "faziam uso estratégico de códigos linguísticos dissonantes na negociação de suas identidades e de sua existência cultural" (BORBA, 2015, p. 93). Se, por um lado, a Linguística Queer talvez tenha olhado mais para performances identitárias lésbicas do que os Estudos Queer em geral, por outro lado, ainda há uma lacuna de pesquisas sobre performances de bissexualidade e performances discursivas relacionadas a práticas sexuais que desestabilizam o binário heterossexual/homossexual. ${ }^{6}$ Em Queerly Phrased, há um só capítulo que se concentra sobre a bissexualidade ("The Elusive Bisexual: Social Categorization and LexicoSemantic Change", de M. Lynne Murphy), e poucas menções à bissexualidade nos outros 24 capítulos. Outros livros importantes da Linguística Queer que foram publicados depois, como Language and Sexuality: Contesting Meaning in Theory and Practice, organizado por Campbell-Kibler et al. (2002) e Speaking in Queer Tongues: Globalization and Gay Language, organizado por Leap e Boellstorff (2004), também contêm só algumas menções breves a pessoas que se identificam como bissexuais, sem analisar explicitamente a linguagem e os discursos usados por elas. Como vimos anteriormente, a falta de estudos de Linguística Queer sobre a bissexualidade não é um fenômeno isolado - há uma grande lacuna de pesquisas sobre a bissexualidade nos próprios Estudos Queer em geral.

Em relação ao estudo de outras performances identitárias e práticas sexuais que desestabilizam o binário heterossexual/homossexual e vão além da definição da sexualidade com base no gênero do/a parceiro/a, a mesma lacuna dos Estudos Queer também aparece na Linguística Queer. Em Queerly Phrased, há um capítulo que procura desestabilizar este binário: "Surrogate Phonology and Transsexual Faggotry: A Linguistic Analogy for Uncoupling Sexual Orientation from Gender Identity", de Bruce Bagemihl. $\mathrm{O}$ autor discute as reações preconceituosas de gays e lésbicas cissexuais a homens e mulheres transexuais homossexuais. Porém, embora o autor faça uma discussão importantíssima sobre preconceito contra pessoas transexuais e mostre como a existência de pessoas trans homossexuais desestabiliza a conexão entre sexo "biológico" e sexualidade, ao deslocar o foco no "sexo" para um foco no gênero, ele acaba por simplesmente reiterar e reforçar a definição de sexualidade baseada no gênero do/a

transgeneridade [...]. Seria simplesmente enganoso igualar esses três grupos com os grupos transgênero ou transexuais da metrópole".

${ }^{6}$ Vale a pena mencionar também a falta de estudos sobre linguagem e heterossexualidade. Nas obras acima citadas, há um capítulo só, no livro de Campbell-Kibler et al. (2002), que discute esse tema: "Playing the Straight Man: Displaying and Maintaining Male Heterosexuality in Discourse”, de Scott F. Kiesling. 
parceiro/a (cis ou trans). Adicionalmente, à diferença dos capítulos focados em identidades de gênero que não se encaixam no binário homem/mulher (e talvez, devido a diferenças culturais, nem na categoria "ocidental" de "transexual" ou "transgênero"), não há capítulos sobre outras maneiras, em outras culturas, de pensar a sexualidade para além do binário heterossexual/homossexual - os capítulos mencionam palavras mais ou menos "equivalentes" a "gay" ou "lésbica" em outros países, mas sempre definindo a sexualidade com base no gênero do/a parceiro/a.

Algo um pouco diferente surge no livro Speaking in Queer Tongues: Globalization and Gay Language, no capítulo "Takatapui, Gay or Just Ho-mo-sexual, Darling? Maori Language, Sexual Terminology, and Identity in Aotearoa/New Zealand" de David A. B. Murray. O capítulo discute como, na língua indígena maori, o termo takatapui denota não somente uma identificação com a homossexualidade, mas também com a etnicidade maori; assim, o autor examina como "uma subjetividade sexual e uma língua minoritárias são posicionadas em relação a uma língua dominante e discursos culturais em uma sociedade pós-colonial" (MURRAY, 2004, p. 175, tradução nossa). Assim, o capítulo discute outras maneiras de pensar performances identitárias de sexualidade - conectandoas a performances identitárias de etnicidade -; porém, novamente, a maneira de categorizar a sexualidade não vai além de uma definição baseada no gênero do/a parceiro/a.

\section{Além da "norma homossexual oculta": dois estudos de caso}

O que gostaria de fazer agora, portanto, é oferecer dois exemplos de estudos recentes realizados no campo da Linguística Queer que vão além da "norma homossexual oculta". Primeiro, olharemos para uma pesquisa sobre performances identitárias de mulheres bissexuais vis-à-vis o apagamento discursivo da bissexualidade no movimento LGBT (LEWIS, 2012). O segundo estudo trata de performances narrativas de praticantes de pegging, uma prática sexual na qual uma mulher penetra um homem heterossexual usando um dildo e cinto, face a discursos que tentam deslegitimar suas performances identitárias de heterossexualidade devido à associação ideológica entre o prazer anal dos homens e a homossexualidade (LEWIS, 2016). Espera-se, ao visibilizar tais temas, contribuir para inspirar uma proliferação de pesquisas no âmbito da Linguística Queer que continuem o processo de desestabilização da "norma homossexual" nos Estudos Queer. Ambos os casos discutidos se encaixam na segunda "fase" da Linguística Queer que Borba identifica - o estudo crítico da heteronormatividade a partir de uma perspectiva linguística -, pois olham para como a heteronormatividade afeta os indivíduos e como esses reproduzem e subvertem discursos heteronormativos (ou homonormativos).

\section{Discursos de combate a preconceitos bifóbicos: entre reiterações e desestabilizações da hétero- e homonormatividade}

Apesar de serem teoricamente incluídas pela letra "B" na sigla, as pessoas bissexuais frequentemente são pouco aceitas nos movimentos LGBT. A bissexualidade é tratada como "só uma fase" antes de se assumir heterossexual ou homossexual e as pessoas bissexuais devem lidar com preconceitos de supostamente serem promíscuas e desconfiáveis. O exemplo seguinte de pesquisa imbrica a Linguística Queer e a Análise da Narrativa (BASTOS; BIAR, 2015) para analisar as construções identitárias performativas e discursos de resistência de ativistas LGBT que se identificam como 
mulheres bissexuais, focando em suas narrativas sobre o processo de sair do armário e sobre estereótipos, discriminações e preconceitos bifóbicos que experimentam na sua militância no movimento LGBT. Os dados foram gerados em entrevistas individuais com três mulheres bissexuais, aqui chamadas de Flávia, Nádia e Olímpia (pseudônimos), que participam de um grupo de ativismo LGBT no Rio de Janeiro, no qual um campo etnográfico de 22 meses foi realizado entre 2010-2012.

Os estereótipos e preconceitos bifóbicos sofridos pelas ativistas bissexuais geralmente entram em duas categorias principais. A primeira é o apagamento da bissexualidade, que envolve a insistência na ideia de que a bissexualidade não existe e que as pessoas ou são heterossexuais ou homossexuais e na noção de que a bissexualidade é só uma "fase" e que o/a bissexual é uma pessoa incerta de ser heterossexual ou homossexual. A segunda é a hiper-sexualização das pessoas que se identificam como bissexuais, que envolve a caracterização do/a bissexual como uma pessoa promíscua que sempre precisa ter relações sexuais com homens e mulheres para sentir satisfação sexual e a noção que pessoas bissexuais são desconfiáveis, incapazes de ter relações monogâmicas e portadoras de doenças. Todos esses discursos preconceituosos tendem a invisibilizar, deslegitimar e estigmatizar as performances identitárias bissexuais, reforçando o binário heterossexual/homossexual e marginalizando os/as ativistas bissexuais dentro do movimento LGBT.

Essas duas categorias de preconceitos tendiam a influenciar as performances narrativas das ativistas, que usavam uma variedade de táticas discursivas para combater os estereótipos. Nas narrativas sobre o processo de sair do armário, as três ativistas tendiam a construir suas bissexualidades como algo duradouro e estável, falando de sentir desejo por meninas desde a infância ou início da adolescência e contando histórias sobre relacionamentos com homens e mulheres ao longo da vida. ${ }^{7}$ Isso pode ser visto como uma resposta às deslegitimações das suas performances identitárias pertencentes à primeira categoria mencionada acima - a negação da existência da bissexualidade e a noção que a bissexualidade é somente uma fase transitória. Veremos, a seguir, um trecho da narrativa de Olímpia, que tinha 17 anos no momento da entrevista.

\begin{tabular}{|c|c|c|}
\hline $\begin{array}{l}003 \\
004 \\
005 \\
006 \\
007 \\
008 \\
009 \\
010 \\
011\end{array}$ & Olímpia & $\begin{array}{l}\text { Ah eu na verda::de, na verdade não tive uma histó::ria de }{ }^{\circ} \text { sair do armário }{ }^{\circ} \text {. } \\
\text { Porque é assim, minha família sempre foi muito:: }(.)<\text { aparentemente liberal }>\text {, } \\
\text { cê sabe. Aí (.) eu fui cresce:ndo né, não sei o quê:: e... gostava de } \\
\text { meni:::no... e aí eu }>\text { olhava para as }<\text { meni:::nas }(.)>\text { mas continuava ficando } \\
\text { com os meninos e continuava olhando para as meninas }<\text {. E eu desde muito } \\
\text { pequena eu não fui a mais feminina mais delicada mais que gosta de } \\
\text { Ba::rbie a mais... a mais padrão feminino. Nunca fui assim. E aí eu: }(.) \uparrow e u, \\
\text { foi foi bem natural assim, foi natural (2.0) Fiquei com: u:ma menina no } \\
\text { colégio, >tipo sei lá na sexta sé:rie }<\text {. [...] ((linhas omitidas nas quais pergunto } \\
\text { sobre o sistema escolar brasileiro)) }\end{array}$ \\
\hline $\begin{array}{l}017 \\
018 \\
019\end{array}$ & Olímpia & $\begin{array}{l}\text { É:. Foi tipo- eu nem lembro qual foi a circunstância, }>\text { acho que foi< tipo } \\
\text { uma brincadeira assi:m, eu gostei:. E eu já tinha um estilão: assim, mais } \\
\text { mais larga:do, mais... [...] ((linhas omitidas nas quais ela conta outros momentos } \\
\text { de perceber que gostava de meninas ou do corpo feminino)) }\end{array}$ \\
\hline
\end{tabular}

\footnotetext{
${ }^{7}$ Interessantemente, as entrevistadas tendiam a falar de seus primeiros beijos com meninas, mas não com meninos, talvez refletindo as expectativas (homo)normativas para histórias de sair do armário e o fato das relações entre mulheres serem consideradas fora da norma e, portanto, eventos "extraordinários" que valiam a pena narrar.
} 


\begin{tabular}{|c|c|c|}
\hline $\begin{array}{l}134 \\
135 \\
136 \\
137 \\
138 \\
139 \\
140 \\
141 \\
142 \\
143\end{array}$ & Olímpia & $\begin{array}{l}{[\ldots]>\text { Eu nunca transei com uma }} \\
\text { menina }<\text {. Mas (.) é é assim, eu nunca tive uma relação com uma menina, } \\
\text { nunca fiquei }>\text { uma semana com uma menina. Eu beijei essa meni::na }<\text {. E e } \\
\text { depois eu reparei que eu gosto de menina, é o o olho, é uma coisa que me } \\
\text { atrai, eu desenho nu feminino. É uma coisa }>\text { que tá dentro de mim }<\text {. Mas aí } \\
\text { eu tou }>\text { como um exemplo os meus amigos ficam falando }<<\text { "Ah, você:::, } \\
\text { você acha que você é. }>\text { É, você é ( }) \text { " e não sei o que. Cara (.) um } \\
\text { menino, ninguém precisa dizer para ele, se ele é heterossexual. Ninguém } \\
\text { precisa dizer para ele que ele é heterossexual e ele não precisa transar com } \\
\text { uma mulher para ele saber que ele é heterossexual. [...] }\end{array}$ \\
\hline
\end{tabular}

Vai além do escopo do presente artigo fazer uma análise detalhada de todos os aspectos da narrativa; portanto, focaremos no fato de Olímpia construir sua bissexualidade como duradoura e estável através do uso de certas táticas de intersubjetividade (BUCHOLTZ; HALL, 2004). Ao insistir na alternância contínua entre se interessar por meninos e meninas ("gostava de meni::no... e aí eu >olhava para as< meni::nas (.) $>$ mas continuava ficando com os meninos e continuava olhando para as meninas<", linhas 5 a 7), ela se vale da tática de autenticação (a construção de uma identidade "real" e "genuína") para estabelecer que sua bissexualidade não é "só uma fase". Ela também se vale da tática de autorização (a legitimação através de uma instituição, autoridade ou experiência) ao contar a história do seu primeiro beijo com uma menina (linhas 10 a 18), uma experiência que avalia positivamente ("eu gostei:", linha 18), para legitimar sua atração por mulheres. Olímpia, a única ativista que não tinha tido relações afetivo-sexuais com uma menina, enfatizou explicitamente a importância do beijo e de sentir desejo por meninas desde a infância, enquanto Nádia e Flávia, ao longo das entrevistas (em trechos não incluídos aqui por questões de brevidade), se concentravam mais sobre a estabilidade da afetividade e do desejo por homens e mulheres desde as primeiras experiências sexuais e/ou afetivas com mulheres.

As ativistas sentiam que deviam provar que suas performances identitárias bissexuais não eram "só uma fase" e que a bissexualidade "realmente existe" para serem aceitas, mas assim reforçavam a ideia de identidades fixas e estáveis que são expressões de uma essência bissexual interior. Olímpia, porém, conseguiu lidar com o apagamento da bissexualidade sem reforçar discursos essencializantes através da identificação e crítica de um padrão duplo: as pessoas que se identificam como heterossexuais (ou homossexuais) não têm que justificar suas performances identitárias, mas as pessoas que se identificam como bissexuais devem "provar" sua bissexualidade (linhas 139-143). Através desse depoimento, que envolveu a tática de adequação, acrescentando as semelhanças (que deveria haver) entre um indivíduo ser aceito como heterossexual (ou homossexual) e ser aceito como bissexual, Olímpia conseguiu defender as performances identitárias bissexuais sem reforçar discursos normativos e essencialistas.

Para responder aos preconceitos hiper-sexualizantes da segunda categoria mencionada acima, particularmente a ideia de que indivíduos que se identificam como bissexuais são pessoas promíscuas e infiéis que precisam constantemente de relações com homens e mulheres para ficarem sexualmente satisfeitas, as ativistas tendiam a usar as táticas de autenticação e autorização para construir performances identitárias de bissexuais "sérias", "monógamas" e/ou "seletivas", insistindo na satisfação sexual com somente um/a parceiro/a e com "só um dos gêneros". No trecho abaixo, Nádia menciona um exemplo de uma piada que ouviu várias vezes em conversas entre mulheres que se identificam como lésbicas que liga diretamente a ideia da pessoa que se identifica como bissexual "precisar" de homens e mulheres à ideia da infidelidade inevitável. 


\begin{tabular}{|c|c|c|}
\hline $\begin{array}{l}935 \\
936 \\
937 \\
938\end{array}$ & Nádia & $\begin{array}{l}\text { "Ah ô!” É aquela piadinha que eu falei ontem. Tipo assim, rola uma piada } \\
\text { entre as lésbicas que é: “Ah:: não se mete com bissexual não. Bissexual... } \\
\text { cê tem cem por cento de chance de sê- sê- ser traída!” Sabe? } \\
\text { E você fica ouvi::ndo essas coisas e "EI! Como assim? [...] ((linhas omitidas)) }\end{array}$ \\
\hline $\begin{array}{l}945 \\
946 \\
947\end{array}$ & Nádia & $\begin{array}{l}\text { Não sou ninfomaNí::aca, eu sou BIssexua:1, hh sabe. } \\
\text { Não vou >estar sempre traindo as }<\text { pesso::as, >não é que tou com mulher } \\
\text { vou trair com homem tou com homem vou trair com mulher }<\text {. }\end{array}$ \\
\hline
\end{tabular}

Nádia enfatiza seu desacordo e sua indignação com os preconceitos através dos alongamentos e as mudanças de velocidade e volume na sua fala e realiza uma performance identitária de mulher bissexual fiel através da insistência em não precisar de um homem quando está em uma relação com uma mulher e vice-versa (linhas 946 a 947), assim construindo uma performance identitária de bissexual monogâmica. Flávia também se valeu de uma tática parecida (em um trecho não incluído aqui), construindo-se como uma pessoa "muito seletiva" que não tem relações com "qualquer um" ou "qualquer uma", frisando que é igualmente seletiva com "ambos" os gêneros. Dessa maneira, as ativistas conseguem combater preconceitos sobre a suposta promiscuidade e necessidade de relações com homens e mulheres para a satisfação sexual; porém, também excluem outras possibilidades da diversidade sexual. Primeiro, tendiam a não contemplar a existência de outras performances de gênero para além do binário cisnormativo homem/mulher e, segundo, não mencionaram a possibilidade de haver pessoas que se identificam como bissexuais que de fato preferem não ter relacionamentos monogâmicos. No entanto, o depoimento focado na monogamia também pode ser visto como uma estratégia política para combater certos preconceitos, visto que Nádia, por exemplo, insistiu na monogamia durante a gravação, mas tinha uma relação aberta nas suas práticas fora do âmbito da entrevista (o que foi conversado com ela durante o campo etnográfico).

Porém, embora as ativistas conseguissem combater os estereótipos hipersexualizantes através dessas táticas discursivas, ao insistirem que não são promíscuas e que são capazes de ter relacionamentos monogâmicos, acabaram por sofrer novamente o apagamento da bissexualidade. As ativistas reclamaram que quando afirmavam estar em relacionamentos monogâmicos, outros membros do grupo LGBT geralmente tentavam classificá-las ou como heterossexuais ou como homossexuais, dependendo do gênero do/a seu/sua namorado/a atual, uma atitude que nega novamente a existência da bissexualidade. Destarte, identificamos a existência de um ciclo vicioso e paradoxal de apagamento e hiper-sexualização da bissexualidade: ao insistir que sempre sentem desejo por homens e mulheres para combater o apagamento da bissexualidade, as ativistas são acusadas de serem promíscuas; para combater esse estereótipo hiper-sexualizante, insistem que são capazes de ser monogâmicas; ao insistir que são monogâmicas, são classificadas como lésbicas ou heterossexuais, o que resulta novamente no apagamento da bissexualidade.

\section{O pegging e a subversão e reforço simultâneos da heteronormatividade}

Nosso segundo exemplo vem de uma pesquisa que se concentra sobre performances identitárias de gênero e sexualidade em narrativas digitais de praticantes de pegging, que é, como mencionamos anteriormente, uma prática sexual na qual uma mulher usa um dildo segurado com um cinto para penetrar um homem (que se identifica como heterossexual) no ânus. Esta prática frequentemente é alvo de preconceitos devido à associação ideológica heteronormativa entre o prazer anal dos homens e a 
homossexualidade. Os dados são fruto de uma etnografia virtual realizada entre 2015 e 2016 numa comunidade on-line para pessoas interessadas no pegging. A comunidade tinha aproximadamente 1600 usuários/as cadastrados/as, a maioria dos/as quais era homens estadunidenses entre 30 e 49 anos. Todas as narrativas foram traduzidas do inglês para o português brasileiro pela presente autora. Através da Análise da Narrativa (BASTOS; BIAR, 2015), a pesquisa visa a entender como os/as praticantes de pegging realizam performances identitárias de gênero e sexualidade nas suas narrativas digitais, como lidam com preconceitos sobre a prática e como subvertem e/ou reforçam discursos ideológicos heteronormativos.

A narrativa seguinte foi postada numa página de discussão na qual a moderadora perguntou se os homens que praticam o pegging tinham sentido dúvidas sobre sua masculinidade ou virilidade devido ao fato de gostarem de ser penetrados por mulheres. Interessantemente, a maioria dos homens respondeu dizendo que nunca começaram a duvidar de sua heterossexualidade, em vez de falar de masculinidade ou virilidade como a moderadora tinha perguntado, mostrando a forte associação ideológica entre masculinidade e heterossexualidade. Um desses usuários é Dave (pseudônimo), cujo perfil diz que é um homem de 59 anos (no momento de compartilhar a narrativa) que vive em uma cidade grande do estado de Texas, nos Estados Unidos. Embora Dave afirmasse nunca ter sentido dúvidas sobre sua performance identitária heterossexual, relatou que sua parceira tinha medo de que ele fosse homossexual por causa de seu gosto por pegging, como veremos a seguir:

\begin{tabular}{|l|l|}
\hline 01 & Na verdade depois das primeiras vezes, menos de dez, foi a minha parceira \\
02 & que começou a ter dúvidas sobre a minha heterossexualidade. Ela \\
03 & simplesmente começou a desenvolver a ideia na cabeça dela de que talvez \\
04 & fosse outra coisa que eu de verdade queria e ela estava ficando mais insegura \\
05 & ou mais segura de que eu queria outra coisa. Ou outra pessoa. O que eu curtia \\
06 & era penoso pra ela. Em trinta anos tentamos fazer isso talvez duas vezes. Uma \\
07 & vez foi um acidente apaixonado. Quero dizer, ela era muito imatura por ter a \\
08 & mesma idade que eu. Bom, eu tinha viajado o mundo inteiro e combatido na \\
09 & guerra e ela deixou a casa da família para o alojamento universitário e depois \\
10 & voltou à casa para ensinar. Ainda um pouco filhinha de papai. Por fim senti a \\
11 & necessidade de dizer que se ela insinuasse que eu era gay mais uma vez eu \\
12 & iria ferir sua cavidade oral. Acho que isso foi bastante macho pra ela. A \\
13 & propósito, eu nunca, com raiva, bateria em mulher alguma. \\
\hline
\end{tabular}

Novamente, vai além do escopo do presente artigo fazer uma análise detalhada de todos os aspectos da narrativa; portanto, nosso foco será como o narrador lidou com o fato de sua parceira duvidar de sua heterossexualidade. Primeiro, Dave investe mais tempo em orientações e avaliações que desqualificam a sua parceira (e.g. caracterizandoa de "imatura", linha 7), assim contribuindo para deslegitimar as opiniões da parceira sobre a sexualidade do narrador, do que em contar eventos para compor a ação complicadora (a parceira começar a acreditar que seu namorado queria se relacionar com homens, linhas 3 a 5). Para explicar como lidou com o problema, Dave introduz a segunda (e última) oração narrativa da ação complicadora: o fato de ter usado a ameaça de violência física (linhas 11 a 12) - agressividade ideologicamente associada com a masculinidade heteronormativa. Na realização da ameaça na narrativa, a escolha das palavras "ferir sua cavidade oral" (linha 12) é particularmente interessante. A escolha lexical do vocabulário clínico, "cavidade oral" em vez de "boca", e o uso do verbo mais formal, "ferir" em vez de "bater", provoca certo estranhamento e talvez sugira um 
distanciamento ou ironia do narrador em relação ao ato violento proposto. Depois, o enunciado "Acho que isso foi bastante macho pra ela" (linhas 12 a 13) serve como resolução implícita da ação complicadora, pois insinua que a parceira parou de questionar a heterossexualidade de Dave. Aqui, vemos novamente a conexão ideológica entre agressividade ou masculinidade hegemônica e heterossexualidade: a performance "macho" foi realizada, e aparentemente serviu para legitimar a performance de heterossexualidade, apesar de homens não heterossexuais também poderem ser agressivos e machistas.

Depois, na coda da narrativa (linha 13), Dave declara que na verdade ele nunca usaria força física contra uma mulher, realizando uma performance de uma masculinidade não violenta e sugerindo que a performance "macho" e agressiva simplesmente fosse uma tática para convencer sua parceira da sua heterossexualidade. Seguindo Michael Kimmel, embora "a violência frequentemente [seja] o sinalizador mais evidente da masculinidade" (1994, p. 148, tradução nossa), muitas vezes o que é mais importante do que a violência em si é a performance da disposição a cometer atos de violência ou do desejo de cometer tais atos. E, como sabemos, uma ameaça pode ter efeitos performativos mesmo se o/a falante não pretende levá-la a cabo (BUTLER, 1997). Narradores/as podem fazer performances que mudam dependendo de como querem ser vistos/as em certo contexto, e seus posicionamentos podem reiterar performances normativas de gênero ou desestabilizá-las. No caso das performances identitárias de Dave, ele usou as expectativas para a masculinidade heteronormativa e "brincou" com elas para defender a legitimidade da sua heterossexualidade não-normativa. A afirmação que ele nunca exerceria violência contra mulheres, na coda da narrativa, também mostra a diferença entre como Dave se posiciona e performa sua masculinidade para sua parceira - quem ele precisa convencer de que ele não é homossexual - e como se posiciona e performa sua masculinidade no espaço da comunidade on-line, onde ele não tem que legitimar sua heterossexualidade e masculinidade para os/as outros/as praticantes de pegging.

Com certeza, a ameaça de violência física, mesmo se não tiver uma intenção de realizá-la, é preocupante. Pode até causar surpresa o fato de um homem que se engaja numa prática aparentemente tão pouco heteronormativa como o pegging fazer uma performance identitária tão hegemônica e heteronormativa. Porém, Susan Lurie (1999) nos lembra que devemos considerar as condições sob as quais os indivíduos têm acesso a performances identitárias emancipatórias e subversivas, pois tais performances frequentemente são mais acessíveis para sujeitos privilegiados. Em outras palavras, ao criticar certo ato de resistência (neste caso, a ameaça) e pensar "Por que a pessoa fez isso se também existem outras opções subversivas?", precisamos lembrar que Dave é colocado em uma posição de sujeito estigmatizado (pela parceira em particular e pela sociedade heteronormativa em geral) e que, em parte devido à força de ideologias heteronormativas, talvez não tenha acesso a performances emancipatórias com menos efeitos (potenciais) conservadores. $\mathrm{O}$ fato do pegging ser pouco visível e pouco aceito na sociedade heteronormativa significa que não há um grande repertório mais amplo de narrativas eventualmente mais emancipatórias e menos normativas sobre a prática. Porém, estão disponíveis grandes repertórios de construções discursivo-identitárias de heterossexualidade normativa e masculinidade hegemônica. 


\section{Linguística Queer e ação social}

A partir da nossa discussão crítica da "norma oculta homossexual" e dos dois exemplos de pesquisa acima, podemos pensar em quais rumos a Linguística Queer pode - ou deve - tomar. Embora as duas pesquisas discutidas tratem de temas bastante diferentes - mulheres bissexuais que são ativistas no movimento LGBT e homens heterossexuais que praticam o pegging -, também têm vários elementos em comum. Primeiro, olham para performances identitárias de sujeitos cujas sexualidades são pouco pesquisadas. Como vimos ao longo do presente artigo, embora a Linguística Queer tenha fugido um pouco da "norma homossexual [gay] oculta" nos Estudos Queer por ter dado mais visibilidade às lésbicas, ainda poderia explorar melhor a bissexualidade e outras maneiras de pensar a sexualidade para além de categorias baseadas no gênero do/a parceiro/a.

Espera-se que os dois exemplos aqui discutidos contribuam para inspirar uma proliferação de pesquisas no âmbito da Linguística Queer que continuem o processo de desestabilização da "norma homossexual". Segundo, ambas pesquisas analisam táticas discursivas de resistência a preconceitos e como subversões da heteronormatividade frequentemente são acompanhadas por reiterações da norma. No caso das mulheres bissexuais, elas tendiam a insistir numa visão essencialista da sexualidade como algo estático e em reforçar a valorização das relações monogâmicas, mas como táticas discursivas para evitar o apagamento e a hiper-sexualização de sua bissexualidade face a discursos preconceituosos.

No caso do adepto de pegging, ele performou uma masculinidade hegemônica em certo momento, mas como uma tática discursiva para defender sua heterossexualidade face a tentativas de deslegitimá-la. Criar inteligibilidade sobre como subversões e reforços da heteronormatividade são realizados através do discurso pode nos ajudar a pensar em como enfatizar o uso de atos de fala e táticas discursivas que desestabilizam certos aspectos da heteronormatividade sem reiterar outros. A repetição desses discursos alternativos e subversivos, por sua vez, pode contribuir para criar maior mudança social, abrindo mais possibilidades para uma grande variedade de performances de sexualidade para além do binário heterossexual/homossexual.

Se, como vimos anteriormente, os estudos da Linguística Queer hoje em dia, na sua segunda fase, tendem a olhar criticamente para a heteronormatividade através de um ponto de vista linguístico, é importante que olhem também para a relação entre heteronormatividade e outras normatividades (homonormatividade, normatividades de raça e classe etc.). Se a segunda fase tende a "investigar como discursos [...] deixam traços na língua, possibilitam a ação social e são, na performance linguística, sustentados ou subvertidos" (BORBA, 2015, p. 94), é de suma importância conectar esse estudo da reiteração ou subversão discursiva não somente à investigação de "como discursos [...] possibilitam a ação social”, mas também tentar colocar isso em prática. A Linguística Queer precisa não somente produzir conhecimento e criar inteligibilidades sobre as relações entre linguagem, gênero, sexualidade e heteronormatividade e sobre como discursos podem possibilitar ação social, mas também construir e visibilizar alternativas a discursos (hétero)normativos marginalizantes e fomentar seu uso, para contribuir para mudanças sociais concretas e importantes. 


\section{REFERÊNCIAS}

AUSTIN, J. L. Quando dizer é fazer: palavras e ação. Tradução de Danilo Marcondes. Porto Alegre: Artes Médicas, 1990 [1962].

BARRETT, R. Is queer theory important for sociolinguistic theory? In: CAMPBELLKIBLER, K. et al. (Org.). Language and Sexuality: Contesting meaning in theory and practice. Stanford: CSLI Press, 2002. p. 25-43.

BASTOS, L. C.; BIAR, L. de A. Análise de narrativa e práticas de entendimento da vida social. D.E.L.T.A, São Paulo, v. 31-especial, p. 97-126, 2015.

BORBA, R. Linguística queer: uma perspectiva pós-identitária para os estudos da linguagem. Revista Entrelinhas, São Leopoldo, v. 9, n. 1, p. 91-107, jan./jun. 2015.

BUCHOLTZ, M.; HALL, K. Theorizing identity in language and sexuality research. Language in Society, v. 33, p. 469-515, 2004.

BUTLER, J. Excitable Speech: A Politics of the Performative. Nova Iorque e Londres: Routledge, 1997.

Problemas de gênero: Feminismo e subversão da identidade. Tradução de R.

Aguiar. Rio de Janeiro: Civilização Brasileira, 2003 [1990].

CAMPBELL-KIBLER, K.; PODESVA, R. J.; ROBERTS, S. J.; WONG, A. (Orgs.). Language and Sexuality: Contesting Meaning in Theory and Practice. Stanford: CSLI Publications, 2002.

CHESEBRO, J. W. Gayspeak: Gay Male and Lesbian Communication. Nova Iorque: Pilgrim Press, 1981.

CONNELL, R. Gênero em termos reais. Tradução de M. Moschkovich. São Paulo: nVersos, 2016.

CORY, D. W.; LEROY, J. P. A Lexicon of Homosexual Slang. In: . The Homosexual and His Society: A View from Within. Nova Iorque: Citadel Press, 1963.

DE LAURETIS, T. Queer Theory: Lesbian and Gay Sexualities. Differences: A Journal of Feminist Cultural Studies, v. 3, n. 2, p. iii-xviii, 1991.

ERICKSON-SCHROTH, L.; MITCHELL, J. Queering Queer Theory, or Why Bisexuality Matters. Journal of Bisexuality, v. 9, n. 3-4, p. 297-315, 2009.

FARRELL, R. A. The Argot of the Homosexual Subculture. Anthropological Linguistics, V. 14, p. 97-109, 1972.

GRICE, P. Lógica e conversação. Tradução de J. W. Geraldi. In: DASCAL, M. (Org.). Fundamentos metodológicos da linguística: Pragmática, v. 4. Campinas: UNICAMP, 1982. p. 81-103.

GUSTAVSON, M. Bisexuals in Relationships: Uncoupling Intimacy from Gender Ontology. Journal of Bisexuality, v. 9, n. 3-4, p. 407-429, 2009.

KIMMEL, M. S. Masculinity as Homophobia. p. 147-151, 2004. Disponível em: $<$ http://eurogender.eige.europa.eu/sites/default/files/Masculinity.pdf $>$. Acesso em: 24 jul. 14. 
LEAP, W.; BOELLSTORFF, T. (Orgs.). Speaking in Queer Tongues: Globalization and Gay Language. Urbana e Chicago: University of Illinois Press, 2004.

LEWIS, E. S. "Acho que isso foi bastante macho pra ela": Reforço e subversão de ideologias heteronormativas em performances narrativas digitais de praticantes de “pegging". 2016. 333 f. Tese (Doutorado em Estudos da Linguagem) - Faculdade de Letras, Pontifícia Universidade Católica, Rio de Janeiro, 2016.

"Não é uma fase": Construções identitárias em narrativas de ativistas LGBT que se identificam como bissexuais. 2012. 267 f. Dissertação (Mestrado em Letras/Estudos da Linguagem) - Faculdade de Letras, Pontifícia Universidade Católica, Rio de Janeiro, 2012.

Teoria(s) Queer e performatividade: mudança social na matriz heteronormativa. In: MACEDO, E.; RANNIERY, T. (Orgs.). Curriculo, sexualidade e ação docente. Petrópolis: DP et Alii, 2017. p. 157-186.

LIVIA, A.; HALL, K. (Orgs.). Queerly Phrased: Language, Gender and Sexuality. Oxford e Nova Iorque: Oxford University Press, 1997.

LOURO, G. L. Um corpo estranho: ensaios sobre sexualidade e teoria queer. Belo Horizonte: Autêntica, 2004.

LUMBY, M. Code Switching and Sexual Orientation: A Test of Bernstein's Sociolinguistic Theory. Journal of Homosexuality, v. 1, n. 4, p. 383-399, verão, 1976.

LURIE, S. Performativity in disguise: ideology and the denaturalization of identity in theory and The Crying Game. The Velvet Light Trap, v. 43, p. 51-62, primavera, 1999.

MOONWOMON, B. Toward a Study of Lesbian Speech. In: BREMNER, S. et al. (Orgs.). Proceedings of the First Berkeley Women and Language Conference. Berkeley, California: Berkeley Women and Language Group, 1985. p. 96-107.

MOTSCHENBACHER, H. Taking queer linguistics further: sociolinguistics and critical heteronormativity research. International Journal of the Sociology of Language, v. 212, p. 149-179, 2011.

MURRAY, D. A. B. Takatapui, Gay or Just Ho-mo-sexual, Darling? Maori Language, Sexual Terminology, and Identity in Aotearoa/New Zealand. In: LEAP, W.; BOELlSTORFF, T. (Orgs.). Speaking in Queer Tongues: Globalization and Gay Language. Urbana e Chicago: University of Illinois Press, 2004. p. 163-180.

MURRAY, S. O. The Art of Gay Insulting. Anthropological Linguistics, v. 21, p. 211-223, 1979.

QUEEN, R. A Matter of Interpretation: The 'Future' of 'Queer Linguistics'. In: CAMPBELL-KIBLER, K. et al. (Orgs.). Language and Sexuality: Contesting Meaning in Theory and Practice. Stanford: CSLI Publications, 2002. p. 69-86.

RODGERS, B. The Queens'Vernacular: A Gay Lexicon. São Francisco: Straight Arrow Books, 1972.

SEDGWICK, E. Epistemology of the Closet. Berkeley e Los Angeles: University of California Press, 1990.

STRAIT AND ASSOCIATES. The Lavender Lexicon: Dictionary of Gay Words and Phrases. San Francisco: Strait, 1964. 
SULLIVAN, N. A Critical Introduction to Queer Theory. Nova Iorque: New York University Press, 2003.

WEBBINK, P. Nonverbal Behavior and Lesbian/Gay Orientation. In: MAYO, C.; HENLEY, N. (Orgs.). Gender and Non-verbal Behavior. Nova Iorque: Springer, 1981. p. 253-259.

WILCHINS, R. Queer Theory, Gender Theory: An Instant Primer. Los Angeles: Alysin Books, 2004.

Recebido em: 10/10/2017

Aprovado em: 21/03/2018

ANEXO: Convenções de transcrição

\begin{tabular}{|l|l||l|l|}
\hline$(1.0)$ & pausa medida (de um segundo ou mais) & $\uparrow$ & subida de entonação \\
\hline$\ldots$ & pausa não medida, longa & $\downarrow$ & descida de entonação \\
\hline$()$. & pausa não medida, breve & $>$ palavra $<$ & fala mais rápida ou acelerada \\
\hline. & entonação descendente / final de elocução & $<$ palavra $>$ & fala mais lenta \\
\hline$?$ & entonação ascendente & $:$ ou $::$ & alongamentos \\
\hline, & entonação de continuidade & {$[\quad]$} & sobreposição de falas \\
\hline- & parada súbita & $(\quad)$ & fala não compreendida \\
\hline$=$ & elocuções contíguas & (palavra) & fala duvidosa \\
\hline sublinhado & ênfase & $((\quad))$ & comentários do/a analista \\
\hline MAIÚSCULA & fala em voz alta / muita ênfase & "palavra" & fala relatada \\
\hline${ }^{\circ}$ palavra ${ }^{\circ}$ & fala em voz baixa & hh & aspiração ou riso \\
\hline
\end{tabular}

